\section{Medicina Baseada em Euidências \\ TRATAMENTO DO CISTO PILONIDAL: CICATRIZAÇÃO POR SEGUNDA INTENÇÃO OU SUTURA PRIMÁRIA EM LINHA MÉDIA?}

A doença pilonidal sacrococcígea é uma inflamação crônica dos seios pós-sacrais que afeta a área da pele posterior ao ânus, recobrindo o sacro na região da fenda interglútea. A melhor opção de tratamento cirúrgico tem por finalidade alcançar a cura por meio de operações de pequena envergadura e pouca complexidade, que permitam rápida integração dos doentes às suas atividades habituais, além de baixas taxas de recorrência. Embora a doença pilonidal seja conhecida há muito tempo e diversas variedades terapêuticas tenham sido propostas, visto que não há consenso sobre a melhor estratégia para abordar a doença pilonidal sacrococcígea, realizou-se uma revisão com o objetivo de comparar a técnica de cicatrização por segunda intenção à técnica de fechamento primário em linha média.

Foi realizada uma busca na literatura eletrônica na base de dados MEDLINE, utilizando os termos "Pilonidal sinus" e "Randomized Controlled Trial". As buscas foram encerradas em maio de 2009. Apenas ensaios clínicos controlados e randomizados publicados em inglês, espanhol ou português foram selecionados para análise. Procedeu-se ainda uma avaliação mais apurada da qualidade dos ensaios, com o objetivo de avaliar a força da evidência produzida por cada estudo e a validade de sua inclusão na revisão. Para isso, utilizamos os critérios elaborados a partir do trabalho de Jadad et al. ${ }^{1}$. Apenas estudos com pontuação igual ou superior a três foram incluídos. Os desfechos analisados foram: tempo para obter cura, tempo para retomar atividades e recorrência.

\section{RESULTADOS}

Esta revisão baseou-se em dados de sete estudos ${ }^{2-9}$.

Tempo para obter a cura. Seis estudos analisaram o tempo para obter a cura como desfecho ${ }^{2-7}$. Três desses não apresentaram os valores de desvio padrão para o cálculo dos intervalos de confiança e, portanto, não foram incluídos na síntese dos resultados ${ }^{2,3,5}$. Os pacientes submetidos ao tratamento com sutura primária obtiveram cura mais rapidamente. A diferença entre as médias variou entre 28 e 63 dias (IC95\% 22-71 dias).

Tempo para retomar as atividades. Quatro estudos analisaram o tempo para retomar as atividades como desfecho ${ }^{3,5,6,7}$. Pode-se calcular o intervalo de confiança de apenas dois trabalhos que apresentaram dados suficientes ${ }^{6,7}$. 0 tratamento com sutura primária mostrou retorno mais rápido às atividades cotidianas. A diferença entre as médias variou entre 25 e 26 dias (IC95\% 22-28 dias).

Recorrência. Sete estudos analisaram recorrência como desfecho ${ }^{2-8}$. O período de seguimento dos pacientes variou entre 12 e 35 meses. Todos os trabalhos mostraram resultados não significantes quanto à diferença entre a sutura primária e a cicatrização por segunda intenção.

\section{CONCLUSÃO}

No tratamento do cisto pilonidal, a síntese da evidência permitiu concluir que a sutura primária em linha média é superior a cicatrização por segunda intenção pelo fato do menor tempo para obtenção de cura e para o retorno às atividades diárias. Não há diferença entre as técnicas quanto ao desfecho recorrência.

Felipe Toyama Aires ${ }^{1}$ Wanderley Marques Bernardo ${ }^{2}$

1. Acadêmico Faculdade de Medicina de Santos - UNILUS, Santos, SP

2. Coordenador Projeto Diretrizes AMB-CFM. Professor de Medicina Baseada em Evidência na Faculdade de Medicina de Santos - UNILUS, São Paulo, SP

\section{Referências}

1. Jadad AR, Moore RA, Carroll D, Jenkinson C, Reynolds DJ, Gavaghan DJ, McQuay HJ. Assessing the quality of reports of randomized clinical trials: is blinding necessary? Control Clin Trials. 1996;17(1):1-12.

2. al-Hassan HK, Francis IM, Neglén P. Primary closure or secondary granulation after excision of pilonidal sinus? Acta Chir Scand. 1990;156(10):695-9.

3. Khawaja HT, Bryan S, Weaver PC. Treatment of natal cleft sinus: a prospective clinical and economic evaluation. BMJ. 1992 May 16;304(6837):1282-3

4. Søndenaa K, Andersen E, Søreide JA. Morbidity and short term results in a randomised trial of open compared with closed treatment of chronic pilonidal sinus. Eur J Surg. 1992;158(6-7):351-5.

5. Mohamed HA, Kadry I, Adly S. Comparison between three therapeutic modalities for non-complicated pilonidal sinus disease. Surgeon. 2005;3(2):73-7.

6. Kareem TS. Surgical treatment of chronic sacrococcygeal pilonidal sinus. Open method versus primary closure. Saudi Med J. 2006;27(10):1534-7.

7. Al-Salamah SM, Hussain MI, Mirza SM. Excision with or without primary closure for pilonidal sinus disease. J Pak Med Assoc. 2007;57(8):388-91.

8. Søndenaa K, Nesvik I, Andersen E, Søreide JA. Recurrent pilonidal sinus after excision with closed or open treatment: final result of a randomised trial. Eur J Surg. 1996;162(3):237-40. 